\title{
El rayo multiplicado: ritos, símbolos e ideología en el carnaval de Santa Cruz de Guamote (Ecuador) y el marcaje de ganado en Moya (Perú). Una lectura comparada
}

Víctor Vimos Vimos*

\begin{abstract}
Resumen
El Rito es un territorio fronterizo entre lo pagano y lo Sagrado. Su EFicaCia modula la Relación del

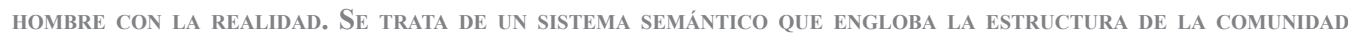
EJECUTORA, ALREDEDOR DE UNA SERIE DE PRÁCTICAS QUE SE DISPONEN TRAS UN OBJETIVO ESPECÍFICO.

Santa Cruz, en Guamote, Ecuador; y Moya, en Huancavelica, Perú, son dos comunidades cuyos ritos PRINCIPALES PERMITEN LEER ESA RELACIÓN DEL HOMBRE CON LA REALIDAD A PARTIR DE UN DESPLIEGUE CEREMONIAL DE ACCIONES, QUE APELAN A LA MEMORIA COLECTIVA COMO REPOSITORIO PRINCIPAL PARA SU REPRODUCCIÓN. LOS CONOCIMIENTOS QUE DE ALLÍ SE DESPRENDEN GANAN VIGENCIA EN LA MEDIDA EN QUE SON ÚTILES PARA LA COTIDIANIDAD de los comuneros. El carnaval de Santa Cruz, y el marcaje de ganado en Moya, son los rituales en los QUE EL UNIVERSO SIMBÓLICO OCCIDENTAL Y LA RACIONALIDAD ANDINA CONSTRUYEN UN LENGUAJE CAPAZ DE REVELAR LA DIMENSIÓN CEREMONIAL DE LA COMUNIDAD, ANTE LA QUE EL RITO ACTÚA COMO RE-ORIENTADOR DE LAS FUERZAS SOCIALES QUE PERMITEN LA CONVIVENCIA COLECTIVA EN ESTOS DOS SECTORES ALTO-ANDINOS DE LA REGIÓN.
\end{abstract}

Palabras Clave: rito - ritualidad - Santa Cruz - Guamote - memoria - Ecuador - Perú.

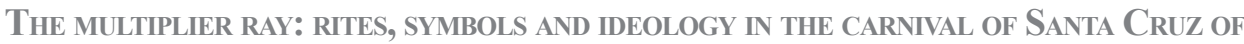
Guamote (Ecuador) and the marking of Cattle in Moya (Peru). A comparative lecture

\begin{abstract}
A RITE IS A BORDER TERRITORY BETWEEN THE PAGAN AND THE SACRED. ITS EFFECTIVENESS MODULATES THE RELATIONSHIP OF MAN WITH REALITY. IT IS A SEMANTIC SYSTEM THAT ENCOMPASSES THE STRUCTURE OF THE EXECUTING COMMUNITY THROUgh OF A SERIES OF PRACTICES THAT ARE ARRANGEd ARound a SPECIFIC ObJeCtive. SANTA CruZ, in Guamote, Ecuador; and Moya, in Huancavelica, Peru, are two communities whose main rites allow us to read that RELATIONSHIP OF MAN WITH REALITY THROUGH A CEREMONIAL DISPLAY OF ACTIONS WHICH APPEAL TO THE COLLECTIVE MEMORY AS THE MAIN REPOSITORY FOR ITS REPRODUCTION. THE KNOWLEDGE THAT EMERGES FROM THERE GAINS VALIDITY INSOFAR AS IT IS USEFUl TO THE DAILY LIFE OF THE COMMUNITY MEMBERS. ThE CARNIVAL OF SANTA CRUZ AND THE MARKING OF CATTLE IN MOYA ARE RITUALS IN WHICH THE WESTERN SYMBOLIC UNIVERSE AND ANDEAN RATIONALITY CONSTRUCT A LANGUAGE CAPABLE OF REVEALING THE CEREMONIAL DIMENSION OF THE COMMUNITY, BEFORE WHICH THE RITE ACTS AS A GUIDING SOCIAL FORCE THAT ALLOWS FOR COLLECTIVE COEXISTENCE IN THESE TWO HIGH-ANDEAN SECTORS OF THE REGION.
\end{abstract}

Keywords: rite - rituality - Santa Cruz - Guamote - Ecuador - Perú.

* Licenciado en Antropología por la universidad Politécnica Salesiana (Ecuador). Maestro en Antropología por la universidad Nacional Mayor de San Marcos (Perú). Ha participado en investigaciones alrededor de la cultura, identidad, patrimonio, ritualidad, literatura, oralidad y memoria, teniendo el enfoque multidisciplinario entre antropología y literatura como base de reflexión. Profesor en la Escuela de Antropología de la Facultad de Ciencias Sociales, de la universidad Nacional Mayor de San Marcos. Correo electrónico: victorvimos@hotmail.com. 
$\mathrm{L}$ a presente investigación centra su atención en dos ritos particulares de las comunidades campesinas de Santa Cruz de Guamote, provincia de Chimborazo, Ecuador; y Moya, Departamento de Huancavelica, Perú.

El Carnaval de Santa Cruz (Ecuador) sucede anualmente entre febrero y marzo, implica la celebración agrícola más importante de la comunidad, se realiza durante ocho días y está compuesto por una serie de actos cuya finalidad es concebida como un pago a la tierra por la cosecha que está a punto de dar su producción. La figura de Santiago Matamoros, presente en esta fiesta con el nombre particular de San Carlitos, está alentada por la memoria colectiva y unida de forma íntima con la celebración. Junto a él, sin embargo, habita otra presencia: el Ushubug, cerro tutelar de los santacruceños, que condensa atención especial durante los días de carnaval. De manera particular, el martes, previo al miércoles de ceniza, la comunidad en pleno realiza una visita al Ushubug: lo atraviesan de orilla a orilla, cantando, bailando, bebiendo. La fe que moviliza esta visita parece dictar buen futuro a quien atraviese el cerro con toda voluntad.

El marcaje de ganado, por su parte, se celebra entre los meses de julio y agosto, representa una práctica de orden ganadero que pone en juego la vida o muerte de los animales. Las familias poseedoras de ganado, con puntualidad, velan ofrendas que entregarán a la montaña. Su nominación local, Wamani, designa la capacidad de su espíritu para intervenir en el destino de los animales, y por esa vía, en el destino de las familias ganaderas entre los moyanos. Una vez veladas estas ofrendas son enterradas en las faldas del cerro que contiene al Wamani. Se rescatan solamente una suerte de hilos de colores, con los que luego se tejerán aretes para las orejas de los ganados que, simbólicamente, serán entregados a los cuidados de la montaña. Aquí, Santiago Matamoros también está presente bajo los nombres de Tayta Shanti, Shantico o Santiago, teniendo como territorio de presencia sobre todo la oralidad de la gente.

Ambos rituales muestran similitudes en un discurso simbólico útil para la vida social de los individuos que lo comparten. La presencia de la montaña en el imaginario de los comuneros y la celebración familiarizada con imágenes de la religión católica, son dos elementos que guían la selección metodológica de estas comunidades, a las que el investigador ha realizado una serie de visitas entre 2013 y 2016, desplegando herramientas de investigación como la descripción densa, entrevista no estructurada, en medio de una observación participante que ha permitido encontrar una serie de detalles aquí descritos.

La imagen de Santiago Matamoros, el santo asociado con el Rayo, relata además la fuerza con que el pensamiento del hombre andino ha digerido las influencias externas, librando un enfrentamiento por el espacio sagrado entre las creencias propias y ajenas, al punto de fraguar formas particulares de manifestar lo religioso.

En este contexto, el presente artículo, asume tres nociones conceptuales para la interpretación comparativa de estos ritos. El rito, definido por Segalen (2005: 30) como,

“...un conjunto de actos formalizados, expresivos, portadores de una dimensión simbólica (que) se caracteriza por una configuración espacio-temporal específica, por el recurso de una serie de objetos, por unos sistemas de comportamiento y lenguaje específicos, y por unos signos emblemáticos, cuyo sentido codificado constituye uno de los bienes comunes de un grupo".

El símbolo, en cuya constitución parece incluir dos niveles de representación social: uno externo, visible, audible, medible (palabras, gestos, imágenes); uno interno, "sicológico y espiritual (...) puede representar algún profundo saber intuitivo que escapa a la expresión directa" (Pérez Taylor, 2003: 116). Esta característica ha signado la mirada que sobre el símbolo se ha vertido. Jung, por ejemplo, valoró de forma principal la parte desconocida a la que hace referencia el símbolo. Lo que sea que allí se aloje, según Jung, "permanece oculto (y no obstante de algún modo revelado en él) e inaprensible para un acercamiento racional" (Lojo, 1997: 51). A pesar de ese territorio inexplorable, Freud atinó a caracterizar como "constante y universal la relación motivada (por contraste o por analogía) que existe entre simbolizante 
y simbolizado" (Ibíd.: 49). En los trabajos de Guenón, esta parte oscura queda casi descartada, dejando que sea la parte tangible la que se imponga como valor principal del símbolo. Que este tenga muchos sentidos incluidos en su materialidad no es, para Guenón, una condición que hable de su metafísica, tanto como de su exactitud (Ibíd.). La precisión para aquello que representa, sin embargo, es un tramo tan vago como perder toda perspectiva en el espacio no legible del símbolo. Todo objeto puede brindar diversas formas de lectura pues son diversos en sí mismos los usos sociales a los que está sometido. Los discursos emitidos por una relación motivada, de los que habló Todorov para referirse al símbolo, son multivalentes y, si bien pueden tener una dirección, una motivación, también, como apuntó Pierre Guiraud, pueden ser "puros, arbitrarios y bipolares" (Ibíd.: 55) como todo lenguaje.

Lo ideológico, y sus marcos conceptuales que abarcarán no solo la referencia ideal ante una realidad que se impone sobre otras, sino la existencia de diversas realidades, materializadas a partir del uso simbólico de los recursos de la naturaleza y la cultura. La definición de Althusser es vital para el sentido de este artículo. Para él, la ideología "es una organización particular de prácticas significantes que constituye a los seres humanos en sujetos sociales, y que produce las relaciones vívidas por las que tales sujetos están conectados a las relaciones de producción dominantes en una sociedad" (en: Eagleton, 2005: 40). No se trata entonces de una condición racional en extremo, pues lo afectivo y lo inconsciente se incluyen dentro de las relaciones vividas como una forma de relación con la realidad. Lo ideológico no aparece como una descripción que constata lo que un grupo humano considera como real. Sino que el "deseo, esperanza y nostalgia" (Ibíd.: 41), serán expresados también desde la creencia ideológica. La experiencia humana en su encuentro con la realidad se potencializa así como una condición indispensable de legitimación de lo ideológico.

Luego de un extenso análisis teórico, observamos que un rito se caracteriza por poseer tres fases definidas: separación, margen y agregación (Segalen, 2005), incluyendo en medio de cada una de ellas estados intermedios o liminales. La primera etapa significará un distanciamiento real del individuo del curso normal de las cosas. La segunda es su transición entre ese curso normal y un nuevo estado. La tercera el retorno al curso normal con un agregado.

Estos estados tienen un tránsito metafórico, materializado en símbolos que representan ese avance. Los roles y comportamientos rituales que cada uno de esos espacios implica, también, diferencian sus características entre sí, ocupando mayor o menor responsabilidad tras el objetivo sagrado y, evidenciando de este modo una forma diferente de jerarquía, un modo distinto de acercamiento a lo divino.

Cabe resaltar que, bajo este contexto, la presente investigación plantea el siguiente esquema como orientador del análisis comparado. En él, se resaltan dos espacios a los que hemos llamado zonas de Intersección, que servirán para observar la forma particular en la que actúa el rito en los momentos de mayor crisis del tránsito metafórico. (Ilustración 01)

Observamos entonces que ambas acciones rituales, en principio, presentan fases diferenciadas.

La fase de separación, en ambos casos, implica un distanciamiento progresivo con aquello que se puede denominar lo cotidiano. Este distanciamiento está determinado por la cercanía con el núcleo del ritual: las reglas que gobiernan la acción de los hombres tienden a volverse cada vez más rígidas en la medida en que el centro mismo de la ritualidad está cerca ejerciendo una diferenciación radical entre lo cotidiano católico y lo específico andino. En el caso de Santa Cruz, por ejemplo, los días previos a la visita a Ushubug están llenos de acciones propias de la iglesia católica: misas, sermones, bendiciones de bastones de mando, una serie de pasos que se van desgastando en intensidad dada la cercanía con el momento liminal. Para el caso de Moya, esta diferenciación está encarnada en la obtención de los objetos rituales: no se trata de elementos relacionados con la iglesia católica (la ausencia de cualquier imagen de Santiago, por ejemplo, ilustra esta intención) sino de objetos relacionados con la naturaleza, con el esfuerzo personal o familiar, con la inversión del resultado de ese esfuerzo, sea en tiempo o dinero, a favor del pago que será destinado al Wamani. 


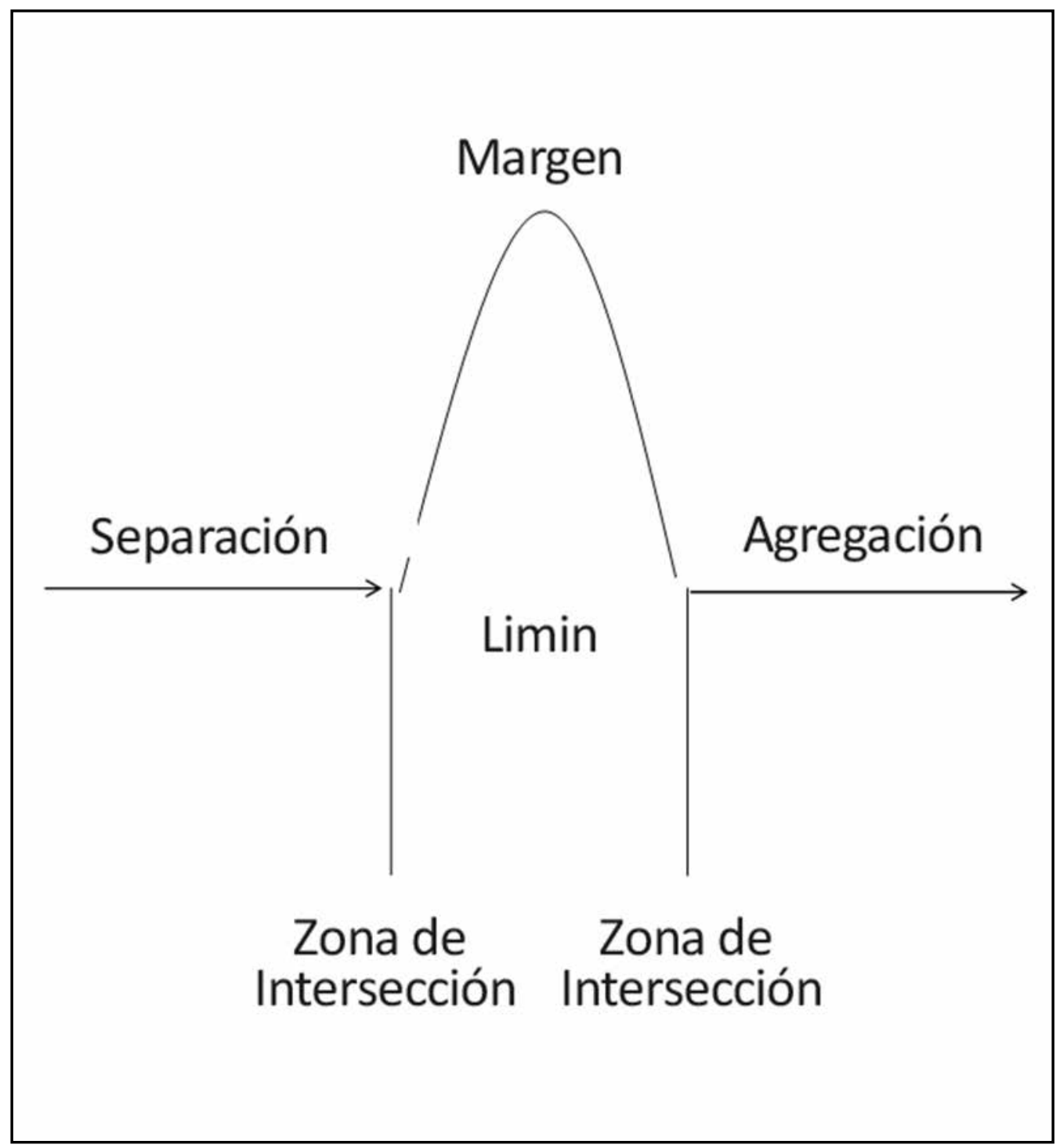

ILustración 1. Modelo DE ANÁLISIS-RITO. Elaborado por el autor. 
La zona de intersección en ambos rituales cumple varias funciones a la vez. Una de ellas, quizá la más evidente, es la de abrir el espacio y tiempo sagrados para su contacto con el espacio, tiempo y actores que vienen del lado profano. Esa apertura, sin embargo, en ninguno de los dos casos es automática pues requiere el cumplimiento de una serie de pasos, establecidos con rigor, que muestran la vigencia del aprendizaje y la memoria comunitaria como un elemento determinante dentro de la acción ritual.

Esta zona de intersección también es el límite de cualquier rezago de lo cotidiano que queda en el grupo social. Al atravesarla, hombres, animales y objetos, sufren una transformación de sustancias referenciales, representativas y funcionales. En el caso de Santa Cruz, los hombres parecen diluir su individualidad en el todo mayor de la comunidad, constituyendo un hecho colectivo capaz de sostener un encuentro con la divinidad. En el caso de Moya, especialmente, esa transformación la viven los objetos rituales que han conformado la mesa de velación previo al marcaje de los ganados: flores, frutas, cigarro, coca, illas, llicta, dejan de ejercer la función representativa de la normalidad para materializarse en realidad en sí mismas. En adelante, y dentro del ritual, una flor será una flor, la coca será la coca, no representarán nada que no sea su propio universo, y como tales podrán ejercer acción específica en el mecanismo del pago al Wamani.

Los espacios de liminalidad, en ambos casos, han sido vistos desde esta investigación como espacios de crisis. La crisis se establece debido a que, para ambos rituales, este espacio implica una acción reiterada de desapego. Para el caso de Santa Cruz, la comunidad entera se ha distanciado de los personalismos, de ese lugar cotidiano donde los conflictos se miden por el nivel de acceso al poder. Aquí, en la montaña, esos vacíos son llenados por la normativa de los valores que en ella habitan: se recuerda a los abuelos, se recuerda a los muertos, se recuerda a los ausentes, en una acción en que la memoria parece vivificar las representaciones sociales que habitan en la montaña. En el caso de Moya, en cambio, ese desapego es generado por la acción de los objetos rituales. Su orientación correcta, en forma de pago, permite que el hombre entregue lo que mejor puede al Wamani, y se quede presto a recibir aquello que el espíritu de la montaña tenga a bien compartirle. En ambos casos las crisis son determinantes para lograr entablar comunicación con lo sagrado.

Un hecho diferencial parece establecerse aquí. Para la comunidad de Santa Cruz el valor que tiene desplazarse alrededor de Ushubug sigue siendo alto en la medida en que legitima el ingreso de lo joven dentro de una comunidad fortalecida moralmente en los valores que han detentado por años los más ancianos. Sin embargo, este ingreso no tiene solo esa vía para legitimarse. Los dirigentes, los jóvenes que han migrado a las ciudades capitales del país, quienes son representantes del desarrollo de la comunidad, cada vez establecen de forma más pronunciada su importancia para la vida de la comunidad. Lo sagrado, entonces, está ingresando a una lista en la que su función también es ejercida por otros mecanismos sociales.

En Moya, en cambio, lo sagrado parece tener una vigorosidad particular debido, probablemente, a que los mecanismos sociales que potencialmente reemplacen o complementen su acción son todavía endebles. La profesionalización, la presencia del Estado en la comunidad, aún son atendidas como lejanas. No queremos decir con esto que los ritos serán doblegados por otras vías de cumplimiento de la demanda (la inclusión de lo joven; la petición de fertilidad para los animales) sino que, al aparecer otras vías de satisfacción de las necesidades sociales, lo sagrado tiende a digerirse con complementos, a convivir con otras prácticas que reciben atención, igualmente, de parte de los hombres.

La segunda zona de intersección, para ambos casos, es la que se produce luego de la fase liminal. Se caracteriza por cerrar el encuentro entre lo sagrado y profano, por ser el punto que deja a cada uno de esos espacios en su lugar de origen y que advierte el regreso del hombre a la cotidianidad. Resulta importante establecer como, al igual que sucedió en la primera intersección, en este segundo cruce, los hombres, animales y objetos rituales sufren un regreso a su forma 
original. Las realidades de las que han sido dueños en la etapa liminal han quedado guardadas para el contacto con lo sagrado. Ahora, en la medida en que se necesita dialogar con un mundo cotidiano es necesario que el lenguaje que se utilice también sea cotidiano.

El tránsito a través de las zonas de intersección permite la alteración de lenguajes, orales, corporales. La crisis que se vive en el espacio liminal no puede ser concebida desde el habla o los comportamientos normales, sino que, si se va a entrar en contacto con la deidad, se requiere un lenguaje elevado capaz de permitir entendimiento e intercambio. En ambos ritos el hombre de las comunidades de Moya y Santa Cruz ejerce esta alteración de lenguajes. No solamente por el uso de palabras especiales (el kwichua es más pronunciado en Santa Cruz; palabras como angorzar, y su significado, son propias y pronunciadas especialmente en el marcaje de ganado en Moya), sino por la labor performática que acompaña a cada una de sus funciones. Hay un comportamiento definido para cada una de las labores rituales, formas de entonar la voz, formas de interpretar el baile, modos en los que la relación social se muestra en proceso de alteración y reacomodo.

La fase de agregación, final en cada uno de los rituales, permite observar el efecto de las acciones humanas frente a lo sagrado. Este efecto se siente en dos vías: la primera, de carácter moral, acerca a los participantes en el rito hacia formas preconcebidas de la coexistencia con los demás, y de esta forma, reorganiza su relación con el mundo; la segunda, que es de carácter simbólico, se ejecuta en la medida en que, en ambos rituales el efecto de lo sagrado en la vida de los hombres está signado por un poder materializado en símbolos.

En el caso de Santa Cruz, los distintos símbolos que siguen a la visita a Ushubug recrean aquello que la montaña ha determinado para la comunidad: unidad, solidaridad, abundancia. En el caso de Moya, los aretes de los animales serán el distintivo de la protección del Wamani, a partir de ellos, quien los vea sabrá que el hombre que se encarga de esos animales está, también, apoyado por la protección especial de los cerros, ha cumplido con su pago.

Cada una de estas fases, en ambos rituales, permite el aparecimiento de roles específicos para los hombres que en ellas participan. Existen, entonces, formas propias de actuar en estos ritos, aprendidas y heredadas como parte de la identidad de los campesinos, y que cumplen un papel generador de memoria y conocimiento.

En Santa Cruz, la relación entre ancianos y jóvenes está mediada por la circulación de información entre unos y otros. La serie de discursos que se establecen entre ellos rigen la recreación de las bases morales y culturales de la comunidad. Antes de visitar Ushubug, por ejemplo, quienes cuidan que los pasos que se estén dando sean los correctos, son los ancianos. Las mujeres, en particular, parecen guardianas celosas de la tradición. No sería bien visto, por nadie, que alguien haga la fiesta fuera de complacencia de los viejos de la comunidad. En Moya, papeles como el del Patrón y el Caporal resaltan en la medida en que vinculan en su contexto formas de acción propiciadoras de la efectividad del rito.

En ambas comunidades, también, el papel social que tiene la montaña es destacable. Para Santa Cruz, Ushubug es un cerro depositario de la memoria y la identidad: el recuerdo de sus abuelos, la forma en la que el cerro alimentaba (siempre en pasado) a la comunidad, son discursos que pueblan el imaginario de los habitantes del sitio. Es una falta de respeto, de consecuencias graves, todavía, pensar que no se visite el cerro el martes de Carnaval, o pensar que se lo visite de mala gana. Sin embargo, elementos como la fertilidad o el deseo de progreso, incluso factores de la salud, que en relatos de los ancianos estaban asociados a Ushubug, cada vez son mencionados menos. Desde la perspectiva de esta investigación, es como si, con el paso del tiempo y los eventos de cambio en la cultura de los santacruceños, el cerro Ushubug estuviera pasando a ser parte de su catálogo cultural de acervos identitarios. Una especie de monumento al que hay que rendirle culto, sobre todo porque, así manda la tradición.

En Moya, en cambio, el cerro, su espíritu, el Wamani, están activos y funcionales para la vida de los campesinos. Si no se cumple con el pago, la vida de los animales, y por extensión, la vida de sus dueños, está en serio peligro. A pesar de que, inclusive, se cuente con veterinarios en 
casa (como es el caso de uno de los caporales de la fiesta) la vida de las reses, su salud, está en constante litigio con el humor del Wamani. Por eso no solo durante el rito se recuerda o se paga al cerro. Cuando un sueño lo menciona, cuando un presentimiento así lo requiere, el hombre moyano debe acudir a las inmediaciones de la montaña y pagar lo que pueda para interceder ante ella. De lo que esa intermediación pueda lograr depende, aún en gran medida, el bienestar de los hombres y, por ende, el bienestar de la comunidad.

Las fases de los rituales y los roles sociales que en ellas se cuentan están gobernadas por una condición común: el cumplimiento de los pasos y los roles que en ellas se dictan en busca de la efectividad ritual.

La efectividad ritual tiene un lugar social en las comunidades de Santa Cruz y Moya. En la primera, el desplazamiento a través del cerro Ushubug permite que, de ser efectivo, los valores fundantes de la comunidad sigan vigentes en la formación intergeneracional. Teniendo en la realidad a gran parte de la población en edad de migrar a la ciudad, siendo esta condición, a la vez, una de las que mayor aporte económico entregan a la vida en la comunidad. La visita a Ushubug busca nivelar esa existencia temporal fuera de la comunidad con los mandatos que implican seguir formando parte de ella. La efectividad de la montaña, asumida por los comuneros bajo las frases de "te va bien", "si vas con fe Ushubug te premia", "es importante visitar al cerro porque si no uno se siente medio extraño", apuntan a la vitalidad de la visión comunitaria. No sirve de nada, todavía en Santa Cruz, tener dinero fruto del trabajo fuera de la comunidad y no invitar, por ejemplo, un plato de comida a los vecinos. De la misma forma, dejar de cumplir con la visita al cerro Ushubug no es visto con agrado pues, se sabe, que ello iguala a los vecinos como comuneros, como indígenas hermanados en la historia y la acción. Bajo ese precepto la efectividad que busca el rito de visita al cerro enmarca los criterios de una comunidad fortalecida, latente, para enfrentar el devenir cotidiano.

Para el caso de Moya, el rito del marcaje de g anado apunta a hacer efectivo el cuidado sobre los animales. Las reses forman parte de la estructura económica de los moyanos y, a modo de ahorro están disponibles para cuando la necesidad así las requiera. Un nivel de inversión de esta magnitud necesita tener las garantías necesarias para poder sostenerse en el tiempo. Cuando se ejecuta el rito al Wamani, sin embargo, no se lo hace solo para solicitar, sino para intercambiar: este, el tiempo de Santiago, es conocido como el tiempo en que los cerros se ponen sedientos. Calmar esa sed de la mejor forma posible es una de las condiciones decidoras de la futura efectividad. El cerro, a cambio, devolverá el esfuerzo procurando la vida y la salud a los animales. Un ejercicio de extensión es el que busca saciar necesidades humanas a partir de estos mismos pagos. No es una esperanza ingenua, sin embargo: la efectividad que logra el rito, si el Wamani es bien satisfecho, puede desbordar la piel de los animales y traducirse en bienestar constante para la familia. El bienestar económico, sin duda, es sinónimo del progreso social y, por ende, la idea de tener un hijo, en el ejemplo específico, se adhiere como condición natural a ello.

Este papel del intercambio prima en la relación de los comuneros de Santa Cruz y Moya, con sus respectivas montañas. No se enfrentan a deidades que solo piden u otorgan, sino que requieren también de parte de los hombres. En la medida en que la comunidad acuda a la visita a Ushubug, por ejemplo, el fortalecimiento de la misma será mucho mayor. Lo será también el bienestar que el Wamani imprima a la vida de los animales, cuando el Patrón haya sabido ser lo suficientemente desprendido como para tratar con igualdad a la montaña. El intercambio, parte fundante de las relaciones sociales y económicas vigentes en estas dos comunidades garantiza también que estos ritos ganen sentido en las nuevas generaciones, y dejan por fuera todo intento de reducirlos desde la religión oficial. Siempre que la estructura económica de estas comunidades siga alineada con formas comunitarias de supervivencia, la ritualidad reflejará mecanismos similares, y la efectividad de los ritos estará conectada con el futuro bienestar de los individuos.

De esto se desprende la idea de que, para ambas comunidades, aquello que es agregado después del rito es, en medida diferenciada, necesario para enfrentar la realidad. Santa Cruz y Moya, en formas diferentes, siguen teniendo espacios donde lo agregado (el poder) después 
del rito ejecuta funciones que no pueden ser ejecutadas por ningún otro elemento. Si bien, como hemos sostenido, existen complementos de satisfacción de necesidades en Santa Cruz, el fortalecimiento comunitario sigue teniendo que ver con la festividad masiva, con la celebración del Carnaval. La visita a Ushubug recrea formas originales de ser santacruceño, algo que es necesario todavía para sus habitantes. Para el caso de Moya, el marcaje de los animales garantiza que durante el año venidero la estabilidad estará asegurada, teniendo solamente que preocuparse por lo aledaño: vacunas para el animal, alimentación, es decir, aquello que se debe cumplir para que el poder efectivo del Wamani siga tiendo efecto.

Hemos señalado antes el comportamiento especial que los símbolos tienen dentro de los ritos aquí descritos. Uno de los que más ha llamado la atención y, puede ilustrar lo que ocurre, de forma general con lo demás, está bajo el nombre de Santiago. Como parte del santoral de la religión católica, Santiago tiene presencia original como un actor decisivo en la guerra. En Europa, la guerra que da contexto a su acción es desatada contra los Moros en la ocupación de la península ibérica. De ahí se desprende el nombre con el que llegará a América: Santiago Matamoros. En las guerras de exterminio y conquista, Santiago, asociado por efectos interpretativos con un ser que ataca desde el aire, asumirá el nombre de Santiago Mataindios, y su crueldad, en tanto la crueldad de los hombres, será una fuente de miedo y distancia con la vida cotidiana.

¿Cómo es que este santo, de naturaleza negativa para la vida de los campesinos, se ha transfigurado en un santo capaz de augurar la ventura?

Su equiparación con el Illapa, dios Rayo, podría tener algo que ver con su relación con la montaña. En los relatos desprendidos de la memoria de los habitantes de las dos localidades, las montañas son portadoras de poderes capaces de generar rayos: en Santa Cruz, Ushubug intercambia rayos con otras montañas del sector; en Moya, los cerros son capaces de recibir rayos como intercambio de energía o ganancia de enfrentamientos con otros cerros. Es una forma de mostrar su poder. El rayo se multiplica en su relación con la montaña, construyendo una naturaleza social en la que todo símbolo será alterado.

Es así que, a pesar de que Santiago esté presente en las dos comunidades, y alrededor de los dos ritos, en esencia, no lo está. No es Santiago, el Mataindios, el católico, el que tiene cabida en esta serie de representaciones. Su nombre, en el caso de Moya, ha sido deformado como una muestra superficial de la operación que ha dado ese resultado. El Thayta Shanti o Shanti, más que una presencia es una forma nominativa del tiempo y el espacio particular en el que se ejecuta el Marcaje de Ganado. Los equivalentes de poder que sobre esa nominación reposan son positivos para los hombres que se relacionan con él, y, en ningún caso, representan una amenaza para la efectividad del rito. Su separación está marcada y diferenciada con el terreno, acción y valores que tiene el Wamani, en ningún caso llegan a cruzarse o establecerse coincidencias en las acciones y efectos de uno y otro. A este punto, en Moya, la parte correspondiente a Tayta Shanti parece la parte más festiva, más celebrativa, menos rígida en tanto a las reglas. Un efecto claro de esto está en las canciones de Santiago, música tradicional en la que se relatan episodios de la vida ganadera. Las letras nuevas, contemporáneas, hablan, en gran medida, de la vida de quien migra a la ciudad, de sacarle la vuelta al marido o la mujer, de tomar cerveza. El desplazamiento entonces es a partir del lenguaje, en la medida en que el territorio de Santiago, Thayta Shanti, lo permite.

No es en el territorio de Wamani, donde cualquier duda o injerencia externa significaría la muerte. Otro de los elementos decidores de esta acción es el de la fecha de celebración de Santiago. No hay rigidez, como antes, en la forma de celebrar: se puede escoger cualquier día en el rango del 24 de julio al 31 de agosto. Esto lo permite el tiempo de Shanti; el tiempo de Wamani, en cambio, es fijo, su velatorio es invariablemente el 24 de julio.

San Carlitos en Santa Cruz tiene un tratamiento similar. A pesar de que se conservan algunas imágenes que lo ligan con su antepasado Santiago, en ellas San Carlitos viste como el rey del Carnaval de Santa Cruz. Sus funciones, más que propiciatorias son celebrativas: en la comunidad, se lo nombra en los discursos que emiten los ancianos como una forma de recordar la pertenencia 
a esta tierra de un ser que hermana, que hace bailar, que da de tomar a todos por igual. Su relación con la fiesta es marcadamente vívida, a tal punto que este tiempo se llama el de Carnaval de San Carlitos. No se trata entonces del santo católico. Y, a pesar de que los esfuerzos de la iglesia han tratado de desterrarlo, de señalar una confusión a la hora de explicar su presencia en la gente, San Carlitos, el carnavalero, en esta comunidad está integrado íntimamente a la fiesta. Las coplas del carnaval, canciones propias de esta época, lo invocan. Las narraciones locales dicen que la fiesta empieza cuando San Carlitos llega a la comunidad. Entre los recuerdos más íntimos de los comuneros reposa las narraciones de sus abuelas, de sus madres, que, a poco de empezar la fiesta, iban describiendo por dónde estaba San Carlitos, cuánto faltaba para que llegue, a quién ya había visitado. San Carlitos, como la fiesta, no se olvida de nadie, y hace que todos disfruten por igual.

En un modo global, Santiago, el católico, nada tiene que ver con los ritos aquí descritos. En su lugar existen símbolos propios de la comunidad transformados en materialidad y sentido. No es poco llamativo, por ejemplo, que Shanti y San Carlitos vivan, ahora, sobre todo, en la oralidad de los campesinos y que a ellos se atribuya el tiempo de la fiesta. Vaciados de su temeridad católica, estos símbolos han sido cubiertos de aquello que es representativo para la comunidad: solidaridad, entusiasmo, goce, amistad; conforman el marco de acción en el que estas nominaciones tienen efecto.

A un nivel micro, ocurre lo mismo con los objetos rituales utilizados durante las fases de estas acciones. En el caso de Santa Cruz, la vestimenta, por ejemplo, deja de ser una limitante determinista del género de quien la usa, y permite que los hombres utilicen atuendos de mujer. Las huarmitukushka aparecen como seres que encarnan la tierra, que son la tierra, y su capacidad para invocar beneficio es respetada por todos los participantes.

El ejemplo de la coca es vital para el caso de Moya. Hemos descrito que los símbolos, dentro de estos rituales son en sí realidades mismas. La coca, por ende, cumple, entre otras, la función de intermediario entre los mundos en contacto en la fase liminal. No lo hace como representante del hombre, no lo hace como planta medicinal, no lo hace por los sentimientos que ella desprende; lo hace como solo ella puede hacerlo en el mundo. La coca, como el hombre vestido de mujer, son organismos naturales legítimos dentro del rito y su acción apunta a sellar circuitos de sentido que no pueden ser cerrados por nadie más.

Si se trata de reemplazar los sistemas de sentido que provienen de un símbolo particular, es decir, reemplazar a un objeto dentro del ritual, se corre el riesgo de generar una grieta de sentido por la que el rito puede empezar a erosionarse. El caso de la ausencia de chicha en la celebración del Carnaval de Santa Cruz puede mostrar, de alguna forma, esto. Al desaparecer la chicha se ha insertado una serie de bebidas (gaseosa, jugos artificiales, etc.) incapaces de movilizar sentido como la bebida de maíz. En el recuerdo de los mayores está clara la imagen de la preparación, la adquisición de ingredientes, las tecnologías caseras que se usaban para dar a luz esa bebida. Ahora, con la chicha desaparecida, ese papel ha sido ocupado por bebidas que nada dicen, en tanto sentido, al colectivo. La ausencia de una preparación que implicaba al colectivo representa un punto débil en tanto relación con lo sagrado. Por esa misma vía se entiende por qué, cada año, el consumo de alcohol viene siendo reducido por los jóvenes catequistas, apegados a la iglesia. Para los ancianos, por ejemplo, visitar al Ushubug debía, como ley, implicar la ingesta de chicha y alcohol. Ahora eso resulta lejano. Como si los latidos del rito encontraran formas de ir mermando.

En Moya, donde la chicha y el alcohol no tienen ausencia ni restricción el imaginario es diferente. La chicha en sí mismo es un elemento integrado en la búsqueda de efectividad ritual. La primera toma de una buena chicha se la debe dar a los animales, ni siquiera al hombre que la prepara. El alcohol permite que los hombres dominen a los animales en el momento de marcarlos: una forma de comunicación que solo puede provenir del desacomodo de los sentidos lógicos y que, en este rito, es indispensable para tener cerca el objetivo planteado. Esto, sin embargo, no significa que los ritos estén cerrados a la incorporación de la realidad exterior. En el caso del marcaje de ganado, por ejemplo, hace pocos años que se ha incorporado las corbatas para el animal, una parodia a las corbatas humanas que hacen que los ganados "se vean elegantes". 
Ambos ritos son espacios abiertos para la integración de realidades contemporáneas.

Los cambios que puedan evidenciarse en ellos siempre deberán ser aprobados por la tradición pero hallarán legitimación en el mayor o menor efecto que logren del lado de lo sagrado. Los ritos aquí descritos ponen en contacto real al mundo profano y al mundo divino, y generan vías de circulación de estos contenidos simbólicos. No hay un Dios, del otro lado, que desconozca la realidad inmediata que está viviendo su creyente. Si esta es de bonanza, los símbolos, incluyendo la oralidad, deberá responder a ella. Si esta es de escases los símbolos, y sin duda, en mayor medida, la oralidad, tenderán a demostrar esto. Y es que en ambos casos la palabra dicha, hablada, tiene un sentido especial al momento de reflejar aquello que rodea las peticiones y los pagos. Nada hay que escape a lo que la palabra nomina, y en estos dos ritos la palabra, en tanto símbolo, tiene un lugar central. La serie de discursos que circulan durante la fiesta de Santa Cruz, por ejemplo, permiten que afloren realidades cotidianas que, en el marco de la ceremonia tienen otra resonancia. Cuando los santacruceños, por ejemplo, van a ingresar a la montaña, piden permiso recordando todo lo que ha pasado en el año. La palabra para ellos es generadora de historia pero también funciona como aglutinadora de deseos: se quiere reencontrarse con aquello que da forma a la comunidad, eso es lo que se pide, en esencia. En el caso de Moya, el pago al Wamani se hace con un lenguaje festivo, recreativo de la necesidad de quien se desprende de lo ganado para satisfacer la sed de su montaña. Sin embargo, en más de un tramo del rito, hay una presencia marcada del silencio, y especialmente, en el núcleo mismo del rito. Aquí podríamos ver cómo, el símbolo, en tanto palabra, sigue transformándose de acuerdo a la necesidad del contacto con lo sagrado. Si la necesidad implica que el sonido de paso al silencio, hay que hacer eso, y dejar que las pulsiones de sentimiento y creencia acarreen la realidad de ese contacto de la mejor manera posible.

Abandonarse, hablando o callando, al dominio absoluto de la fe es un paso constante en estos rituales. En un sentido ideológico, para los habitantes de Santa Cruz y Moya, lo que conocen por fe implica una serie de acciones ejercidas en busca de un resultado positivo para su vida. En medio, esas acciones están íntima y determinantemente vinculadas a la relación con el espacio sagrado de sus comunidades. La aceptación de esas acciones necesarias funciona en dos sentidos: el primero, esas acciones son orientadoras de la formación moral que permite la convivencia en comunidad; segundo, esas acciones naturalizan esa formación al punto de convertirla en normal. Los criterios de norma, en sentido obligatorio, no existen dentro de estos rituales. No es pesado ni implica un sacrificio involuntario ejercer acción en el ritual. Al contrario, es deseable el sacrificio que se realice, en la medida que este implique ser parte de ese todo que se pondrá en contacto con lo sagrado.

Esa naturalización de normativas morales abarca comportamientos alrededor de símbolos y formación de jerarquías. Su efecto, sin embargo, no está limitado al tiempo y espacio del rito, sino que se extiende en la medida en que se permite afectar la vida cotidiana de los creyentes.

Ahora, dentro del ritual, en Moya y Santa Cruz, esta investigación propone que existen momentos de crisis ideológica que son necesarios para readecuar las jerarquías y relaciones entre lo pagano y lo sagrado. En el caso de la comunidad guamoteña, por ejemplo, a sabiendas de que gran parte de sus migrantes son jóvenes que dejan de utilizar el kwichua como lengua de relación con los comuneros, su inserción dentro del rito desencadena una serie de dudas en el sentido de la efectividad de las acciones comunitarias frente a lo sagrado. No se pone en duda la fe. Se pone en duda la capacidad que tengan los nuevos habitantes de Santa Cruz, los migrantes, de cumplir con los pasos que esa fe implica.

Sugerimos que por esta misma vía el rito es un elemento equiparador de esa crisis, pues, en tanto siga siendo efectivo, esas dudas seguirán teniendo formas de convivencia aceptables en la comunidad. Si ellas fallaran, es decir, si los pasos que dictan comportamientos morales fueran desoídos probablemente esa crisis ideológica apuntaría hacia una modificación en la forma de otorgarle sentido a la realidad. 
Para el caso de Moya, la crisis parece relacionada con efectos históricos cercanos. Los relatos de cómo las montañas eran vistas como una opción para perder la vida durante los años de guerra interna en el Perú, permiten miran una inversión en el sentido dador y protector del Wamani. Hacer la fiesta, en ese contexto, implica apaciguar esa posibilidad, reencaminar la creencia de los hombres hacia la acción de las montañas, equilibrar la realidad.

En un sentido amplio, la ideología plasmada por estas comunidades parece convivir con otras fuentes de sentido e interpretación de la realidad. No se trata de apartar o luchar, por ejemplo, contra la doctrina católica. Cada una tiene un radio de acción determinado, y en cada una el hombre andino debe comportarse como es necesario. Todo lo que aporta para su bienestar será bienvenido. Será celebrado.

Hemos observado la acción diferenciada de dos rituales en dos comunidades altoandinas. Las transformaciones simbólicas y sociales que en ellos operan, poseen un nivel de eficacia insustituible, todavía, en cada una de estas poblaciones. Relevante es observar, además, como la memoria es un hilo conductor de esa eficacia, pues presente en todos los estados descritos del ritual, opera no solo como una fuente de un tipo de conocimiento específico sino como un espacio que genera nuevos conocimientos. Lo identitario, lo grupal, lo oral, lo ideológico, están en un diálogo sostenido con la memoria, y constituyen, desde esa perspectiva, territorios de resistencia frente al silencio homogeneizador con el que la contemporaneidad intenta domesticar y neutralizar estas vías de lo sagrado. Hacia el encuentro con Ushubug, hacia el encuentro con Wamani, a través de una memoria que siempre se está escribiendo. 


\section{Bibliografía}

Aguilo, F. 1985, El hombre de Chimborazo, Abya Yala, Quito.

Alcoser, M., 1980, Historia de Guamote. Riobamba, Imprenta Municipal de Riobamba, Ecuador.

Aldana, U. et al. 2015, La violencia infantil y el entorno doméstico: puntos de partida para una propuesta de prevención en Huancavelica, IEP Instituto de Estudios Peruanos, Lima.

Anuario Geográfico Departamental: Perfil Antropográfico de Huancavelica, 1990, Fondo Editorial de la Sociedad Geográfica de Lima, Lima.

Arroyo Aguilar, S. 1987, Algunos aspectos sobre el culto a Tayta Wamani, Lima.

Bartra, R. 2006, Antropología del cerebro: la conciencia y los sistemas simbólicos, Fondo de Cultura Económica, México D.F.

Botero L.F. 1990, Chimborazo de los Indios, Abya Yala, Quito.

Caillois, R. 2008, El hombre y lo sagrado, Fondo de Cultura Económica, México D.F.

Choy, E. 1958, "De Santiago Matamoros a Santiago Mataindios2, en: Revista del Museo Nacional, Tomo XVII, Lima, Perú, pp. 152-272.

Chuquimarca, L. 2008, "Análisis de la transición de los sistemas productivo agrícolas en la Sierra ecuatoriana: una aproximación desde la economía ecológica para el caso de dos comunidades de Guamote, Chimborazo", Tesis inédita de la Maestría en Economía con Mención en Economía Ecológica, Facultad Latinoamericana de Ciencias Sociales, Quito, Ecuador.

Las comunidades campesinas en la Región Huancavelica. 2008, Contexto Social, Económico e Institucional de la Región Huancavelica, Asociación Servicios Rurales, Lima.

Crisóstomo Meza, M. 2009, Mujeres y Fuerzas Armadas en un contexto de Violencia Política: los casos de Manta y Vilca en Huancavelica, IEP Instituto de Estudios Peruanos, Lima.

Díaz Cruz, R. 1998, Archipiélagos rituales: teorías antropológicas del ritual, Anthropos Editorial, México D.F.

Eagleton, T. 2005, Ideología, Paidos, Barcelona.

Eliade, M. 1968, El mito del eterno retorno, Emecé Editores, Buenos Aires.

Eliade, M. 1974, Imágenes y símbolos: ensayos sobre el simbolismo mágico religioso, Editorial Taurus, Madrid.

Elias, N. 1994, Teoría del símbolo, Ediciones Península, Barcelona.

Estermann, J. 1998, Filosofía Andina: estudio intercultural de la sabiduría autóctona andina, Abya Yala, Quito.

García Miranda, J.J. 2010, Las fiestas agroganaderas y Santiago Apostol. Ayacucho, Perú.

Gobierno Autónomo Descentralizado de la Provincia de Chimborazo, 2011, Plan de Desarrollo y Ordenamiento Territorial de Chimborazo, Riobamba, Ecuador.

Guidens, A. (Ed.). 1993, Emilie Durkheim: escritos selectos, Ediciones Nueva Visión, Buenos Aires.

Heidini, 1998, El Carnaval de Guamote, Riobamba, Pedagógica Freire, Ecuador.

Iturralde, D. 1980, Guamote, Campesinos y Comunas. Otavalo, IOA Instituto Otavaleño de Antropología, Otavalo, Ecuador.

Instituto Nacional de Estadísticas y Censos, 2014, Encuesta Nacional de Empleo, Desempleo y Subempleo. Indicadores Laborales, Quito, Ecuador.

Lavalleé D., Julien, M. 1983, Asto: curacazgo prehispánico de los Andes Centrales, IEP Instituto de Estudios Peruanos, Lima.

Leach, E. 1993, Cultura y comunicación: la lógica de la conexión de los símbolos, Siglo Veintiuno Editores, Madrid.

Lemlij, M. y Millones, L. 2009, Guerra y fe en los Andes, Fondo Editorial SIDEA, Lima.

Leví-Satruss, C. 1987, Antropología Estructural, Editorial Universitaria, Buenos Aires.

Lojo, M.L. 1997, El símbolo: poéticas, teorías y metatextos, UNAM, México D.F.

Malinowski, B. 1985, Magia, ciencia y religión, Editorial Planeta- De Agostini S.A., México D.F.

Massuh, V. 1965, El rito y lo sagrado, Editorial Columbia, Buenos Aires.

Mauss, M. 1970, Lo sagrado y lo profano: Obras Completas, volumen I. Barcelona: Barral Editores.

Millones, L. 2014, “Estudio Introductorio", en: Millones, L. (ed.) Por la mano del hombre: prácticas y creencias sobre curanderismo y chamanismo en Perú y México, Fondo Editorial de la Asamblea Nacional de Rectores, Lima.

Mucchielli, R. (1968). Introducción a la sicología estructural. Barcelona: Anagrama. 
Organización Internacional para las Migraciones: Diagnóstico sobre la trata de personas en los cantones Colta y Guamote, Provincia de Chimborazo. 2012. Quito: Ecuador.

Osvaldo Urbano, H. 1976, "Hacia una ritología andina”, en: Allpanchis, volumen IX, pp. 3-10.

Pérez Taylor, R. 2003, "Por una antropología simbólica", en: Weinberg, L. (ed), Ensayo, Simbolismo y Campo Cultural, UNAM, México D.F., pp. 103-128.

Pico W. y Pico, A. 2011, Cuerpo Festivo: personajes escénicos en doce fiestas populares del Ecuador, Ministerio de Cultura del Ecuador, Quito.

Ramírez, M.T. 2011, “Teoría y Crítica de la Ideología en Luis Villoro", en: Signos Filosóficos, volumen XIII, número 25, Universidad Michoacana de San Nicolás de Hidalgo, Michoacán, pp. 121-147.

Rodríguez Saltos, R. 1983, Guamote: ayer y hoy. Riobamba, Editorial Pedagógica Freire.

Sánchez Garrafa, R. 2014, Apus de los cuatro suyos: construcción del mundo en los ciclos mitológicos de las deidades montañas, IEP Instituto de Estudios Peruanos, Lima.

Segalen, M. 2005, Ritos y rituales contemporáneos, Alianza Editorial, Madrid.

Taipe Campos, N.G. 1998, "Apropósito de las memorias de "Santiago Azapara Gala", en: Zúñiga Segura, C., Memorias de Santiago Azapara Gala Gran Señor de Tayacaja, Lima, Perú, pp. 4-6.

Tomoeda, H. 1993, "Los ritos contemporáneos de camélidos y la ceremonia de la Citua", en: Senri Ethnological Studies, $\mathrm{N}^{\circ}$ 37, Lima, Perú, pp. 189- 305.

Todorov, T. 1992, Simbolismo e interpretación, Monte Ávila Editores, Caracas.

Turner, V. 1967, "La selva de los símbolos: aspectos del ritual ndembu", Siglo Veintiuno Editores, Madrid. 1988, El proceso ritual, Editorial Taurus, Madrid.

Ulloa, J.B. 2014, Tenencia de la tierra en Guamote, Chimborazo, en Casa de la Cultura Ecuatoriana Benjamín Carrión, número 30. Riobamba, Ecuador.

Zizek, S. 1992, El sublime objeto de la ideología, Siglo Veintiuno Editores, México. 